九州大学学術情報リポジトリ

Kyushu University Institutional Repository

Sex-conversion from Male to Female during Somatic Embryogenesis from Protoplasts in Asparagus (Asparagus officinalis L.)

Maeda, Tomoo

Plant Ecochemical Research Center, Hokkaido

Ozaki, Yukio

Faculty of Agriculture, Kyushu Unviersity

Sonoda, Takahiro

Fukushima Prefectural Agricultural Experimetn Station

Inoue, Nobuhisa

他

https://doi.org/10.5109/4671

出版情報：九州大学大学院農学研究院紀要. 50 (2)，pp.585-592，2005-10-01. Faculty of Agriculture, Kyushu University

バージョン：

権利関係 : 


\title{
Sex-conversion from Male to Female during Somatic Embryogenesis from Protoplasts in Asparagus (Asparagus officinalis L.)
}

\section{Tomoo MAEDA ${ }^{1}$, Yukio OZAKI*, Takahiro SONODA ${ }^{2}$, Nobuhisa INOUE ${ }^{3}$, Kumiko NARIKIYO ${ }^{4}$ and Hiroshi OKUBO ${ }^{5}$}

\author{
Laboratory of Agricultural Ecology, Division of Agricultural Ecology, \\ Department of Plant Resources, Faculty of Agriculture, \\ Kyushu University, Fukuoka 811-2307, Japan \\ (Received June 30, 2005 and accepted July 26, 2005)
}

\begin{abstract}
Sex-converting mutation from male to female was identified during somatic embryogenesis from protoplasts in asparagus. Although modification of allozyme genotypes from heterozygous to homozygous occurred in three loci, $M d h-1, M d h-2$ and $I d h-1$, accompanied with sex-conversion, genotypes of sex-converted and control plants in $P g m-1$ and $S k d h-1$ loci were identically heterozygous. Relative DNA contents of sex-converted and control plants estimated by flow cytometric analysis were similar, and gametophytic fertility of the sex-converting mutant as female parent was also confirmed by artificial pollination. From these results, the sex-conversion in the current study might be the result of the somatic mutation, such as somatic crossing-over, one of the chromosomal rearrangements.
\end{abstract}

\section{INTRODUCTION}

Asparagus (Asparagus officinalis L.) is a dioecious plant, and its sex expression is controlled by a single locus located on the L5 chromosome (Löptien, 1979). The genotypes of male and female are heterozygous ( $\mathrm{Mm}$ ) and homozygous recessive ( $\mathrm{mm}$ ), respectively (Sneep, 1953). There are generally three types of asparagus hybrid, namely clonal, double and population hybrids, depending on seed harvesting methods. Besides them, there are a few vitroclone cultivars. The vitroclone cultivars are asexually propagated through somatic embryogenesis from callus tissue originated from young spears or protoplasts.

Specific genetic modifications responsible for somaclonal variation have been discussed extensively (Larkin and Scowcroft, 1981; Evans et al., 1984). Commercial micropropagation of clones requires regenerated plantlets to be genetically uniform. It is, therefore, necessary to establish reliable techniques to maintain their genetic stability. If in vitro techniques promote genetic variation, it is important to identify the factors caus-

1 Plant Ecochemical Research Center, Hokkaido 061-1374, Japan

2 Fukushima Prefectural Agricultural Experiment Station, Fukushima 963-8041, Japan

${ }^{3}$ Food Research Institute, Hokkai Can Co., Ltd., Hokkaido 047-0031, Japan

${ }^{4}$ Laboratory of Horticultural Science, Division of Agricultural Botany, Department of Plant Resources, Graduate School of Bioresource and Bioenvironmental Sciences, Kyushu University, Fukuoka 812-8581, Japan

5 Laboratory of Horticultural Science, Division of Agricultural Botany, Department of Plant Resources, Faculty of Agriculture, Kyushu University, Fukuoka 812-8581, Japan

* Corresponding author (E-mail: ozaki@farm.kyushu-u.ac.jp) 
ing the variation and its extent. Factors for somaclonal variation include single nucleotide changes (Dennis et al., 1984), chromosome number changes (Karp et al., 1982; McCoy et al., 1982), chromosomal rearrangements (McCoy et al., 1982; Orton, 1983) and so on. Polyploidy and aneuploidy have been often observed among plants regenerated from tissue cultures (Hammerschlag, 1992) and these changes have been shown to lengthen the duration of cell culture (Skirvin and Janick, 1976). Determination of the ploidy of cultured tissues is one of the most effective methods to monitor and minimize the somaclonal variants. Ploidy levels were determined by counting the somatic chromosomes, and also estimated by measuring the length of stomatas. The procedures are still difficult and/or time consuming in asparagus, so that the efficient analytical methods for determination of ploidy levels have long been desired. Recently, flow cytometry has become a rapid and useful tool for estimation of genome size and ploidy levels in several crops (Baird et al., 1994; Martínez et al., 1994; O’Brien et al., 1996; Ollitrault-Sammarcelli et al., 1994; Ozias-Akins and Jarret, 1994). Ozaki et al. (1998) reported that flow cytometry was also applicable to asparagus.

Sex-converted asparagus plants from male to female were found during somatic embryogenesis from protoplasts in this study. Allozyme analysis and flow cytometry were applied to clarify the mechanism of the sex-converting mutation during somatic embryogenesis.

\section{MATERIALS AND METHODS}

\section{Protoplast culture}

Callus induction and protoplast cultures were carried out as described by Kunitake and Mii (1990). Embryogenic calli were obtained from soft calli of vitroclone asparagus male cultivar 'Festo' by subculturing on MS medium supplemented with $1 \mathrm{mg} / \mathrm{/} 2,4-\mathrm{D}, 1 \mathrm{~g} / \mathrm{l}$ L-glutamine, $3 \%$ sucrose and $0.2 \%$ Gelrite. After embryogenic calli were pretreated for 4-7 days by suspending in 1/2 MS liquid medium with $1 \%$ sucrose, they were gently squashed and incubated with $10 \mathrm{ml}$ of filter-sterilized enzyme solution containing $2 \%$ Cellulase Onozuka RS (Yakult Pharmaceutical Co. Ltd., Japan), 0.5\% Macerozyme R-10 (Yakult Pharmaceutical Co. Ltd., Japan), 0.05\% Pectolyase Y-23 (Seishin Pharmaceutical Co. Ltd., Japan) and $0.6 \mathrm{M}$ sorbitol at $\mathrm{pH} 5.7$. The mixture was incubated for $6 \mathrm{~h}$ at $25^{\circ} \mathrm{C}$ to liberate protoplasts. The protoplasts were collected by filtration through a nylon sieve $(60 \mu \mathrm{m})$ and washed twice with $0.6 \mathrm{M}$ mannitol solution after centrifugation $(100 \times \mathrm{g}$ for $5 \mathrm{~min})$.

The protoplasts were embedded in $0.1 \%$ Gelrite-solidified 1/2 MS media containing $1 \mathrm{mg} / \mathrm{l} \mathrm{NAA}, 0.5 \mathrm{mg} / \mathrm{l}$ zeatin, $1 \mathrm{~g} / \mathrm{L}$-glutamine, $0.6 \mathrm{M}$ glucose and cultured at a density of $1 \times 10^{5}$ cells $/ \mathrm{ml}$ in $60 \times 15 \mathrm{~mm}$ plastic petri-dishes containing $3 \mathrm{ml}$ of culture medium. All dishes were sealed with Parafilm ${ }^{\circledR}$ and maintained at $25^{\circ} \mathrm{C}$ in the dark for 30 days. Formed colonies were subcultured on MS medium with $3 \%$ sucrose for 30 days, and embryogenic calli developed from the colonies were also subcultured on the medium of the same constitution until plant regeneration through somatic embryogenesis.

Three hundred and twenty five plants were established from 650 germinated embryos and transplanted in an open field. Sex expression of the regenerated plants was investigated in the field. There were two female plants considered to be sex-converted 

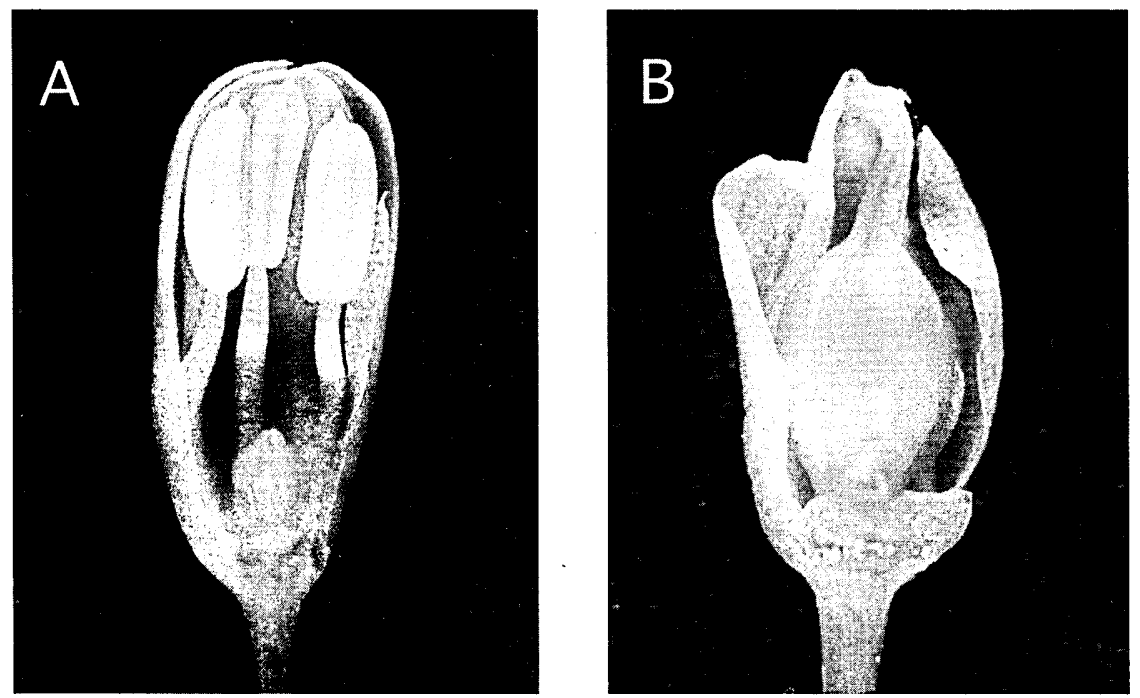

Fig. 1. Flowers of control (A) and sex-converted (B) plants in 'Festo'.

plants, although almost all the flowered plants were male (Fig. 1).

Ploidy, allozymes and gametophytic fertility of one sex-converted female plant (coded as FP-1) and five male plants, (coded as FP-2, FP-3, FP-4, FP-5 and FP-6) were analyzed.

\section{Allozyme analysis}

Spears of the sex-converted (FP-1) and control (from FP-2 to FP-6) plants were used for enzyme extraction. Each sample was homogenized in pre-cooled extraction buffer prepared as described by Wendel and Parks (1982), and crude enzyme extracts were prepared for horizontal starch gel electrophoresis. Genotypes of eight enzyme loci in five enzyme systems, AAT, IDH, MDH, PGM and SKDH, were scored. Genetic basis and allozyme determination of the eight loci followed the previous reports (Ozaki et al., 2000a, 2000b)

\section{Ploidy analysis}

Flow cytometric analyses were conducted with a Partec PA Ploidy Analyzer (Germany) equipped with DAPI filter and Multicycle for MS-DOS software to measure nuclear DNA content. Pieces of phylloclade in each plant were chopped using a sharp razor blade in nuclei extraction buffer (High Resolution DNA Kit, Partec). The suspension containing the released nuclei was passed through a $50 \mu \mathrm{m}$ filter. The nuclei filtrates were stained with four times volumes of staining solution (High Resolution DNA Kit, Partec) containing 4'-6-diamidino-2-phenylindole (DAPI) for more than one min. Fluorescent intensities of sex-converted and control plants were compared in this experiment. Haploid (97SA-003, a gynogenetic haploid plant obtained from the crosses 
between diploid and tetraploid), diploid ('Cito'), triploid ('Hiroshima Green') and tetraploid ('Seto Green') plants were also examined as standards. At least 7,000 nuclei were counted for each sample, and relative DNA content was determined according to the prominent peak in each sample.

\section{Gametophytic fertility of sex-converted plant}

The FP-1 and another control female plant, Welcome-9201-6 (selected from 'Welcome') were used for investigating gametophytic fertility as seed parents. Artificial pollination with three male plants, $\mathrm{GlS}_{1} \mathrm{~F}_{1}-16-2-6-3, \mathrm{GlS}_{1} \mathrm{~F}_{1}-16-2-6-6$ and $\mathrm{GlS}_{1} \mathrm{~F}_{1}-16-2-6-17$, randomly selected from the progenies of 'Gijnlim', was made in the middle of March 1999 in a greenhouse. Fruits were harvested at maturity on 24 June 1999 , and the number of seeds and the average seed weight were investigated in each cross.

\section{RESULTS}

\section{Allozyme analysis}

No variation of allozyme genotypes was observed among six plants from FP-1 to FP-6

$(+)$

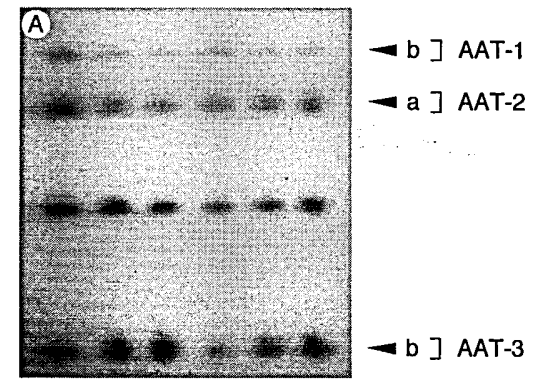

$(+)$

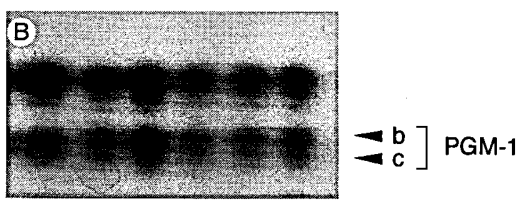

$(+)$

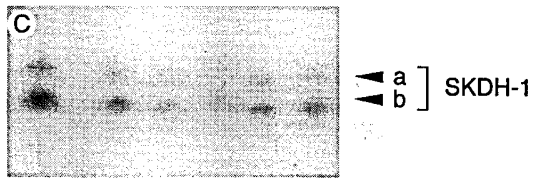

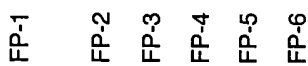

Fig. 2a. Allozyme banding patterns in sex-converted (FP-1) and control (FP-2, 3, 4, 5 and 6) plants in asparagus. A: AAT, B: PGM, C: SKDH.
$(+)$

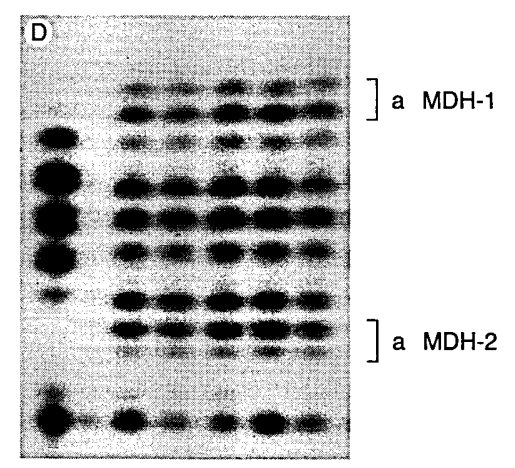

$(+)$

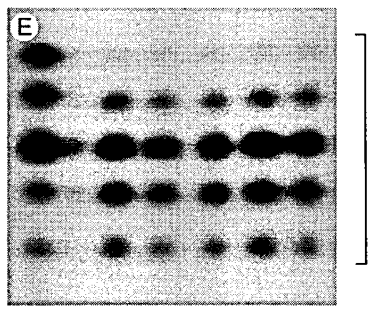

IDH-1

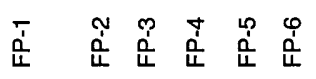

Fig. 2b. Allozyme banding patterns in sex-converted (FP-1) and control (FP-2, 3, 4, 5 and 6 ) plants in asparagus.

D: MDH, E: IDH. 
at five loci of "bb" in Aat-1, "aa" in Aat-2, "bb" in Aat-3, "bc" in Pgm-1 and "ab" in $S k d h-1$ (Fig. 2a). There was also no difference in the genotypes among the five male plants at three loci of "an" in $M d h-1$, "an" $M d h-2$ and "an" in $I d h-1$ (Fig. 2b). There were, however, differences of the genotypes between the males and the female at three loci, "an" vs. "nn" in $M d h-1$, "an" vs. "nn" in $M d h-\mathcal{Z}$ and "an" vs. "aa" in $I d h-1$, respectively.

\section{Ploidy analysis}

Fluorescent intensities at prominent peaks in four standard plants, haploid, diploid, triploid and tetraploid, were 50.0, 100.4, 157.2, 215.8, respectively. Those in the sex-converted and control plants were 107.45 and 104.41 , respectively, with no statistical significant difference to diploid value at $\mathrm{P}=0.05$ by t-test (data not shown).

\section{Gametophytic fertility of sex-converted plant}

Table 1 indicates the results of crosses. Crosses with the three male parents to the FP-1 resulted high values (80.1-94.8\%) of fruit set (Fig. 3) as well as the crosses to the control plant (88.6-100\%). There were little differences in the average number of seeds

Table 1. Fruit and seed sets with artificial crosses in sex-converted and contol plants.

\begin{tabular}{llccccc}
\hline Seed parent & Pollen parent & $\begin{array}{c}\text { No. of } \\
\text { flowers } \\
\text { pollinated }\end{array}$ & $\begin{array}{c}\text { No. of fruits } \\
\text { harvested } \\
(\%)\end{array}$ & $\begin{array}{c}\text { No. of } \\
\text { seeds } \\
\text { harvested }\end{array}$ & $\begin{array}{c}\text { Average no. } \\
\text { of seeds per } \\
\text { fruit }\end{array}$ & $\begin{array}{c}\text { Average } \\
\text { weight of a } \\
\text { seed (mg) }\end{array}$ \\
\hline FP-1 & $\mathrm{GlS}_{1} \mathrm{~F}_{1}-16-2-6-3$ & 151 & $121(80.1)$ & 360 & 2.98 & 34.2 \\
(Sex-converted) & $\mathrm{GlS}_{1} \mathrm{~F}_{1}-16-2-6-6$ & 149 & $121(81.2)$ & 360 & 2.98 & 31.9 \\
& $\mathrm{GlS}_{1} \mathrm{~F}_{1}-16-2-6-17$ & 155 & $147(94.8)$ & 351 & 2.39 & 33.6 \\
Welcome-9201-6 & $\mathrm{GlS}_{1} \mathrm{~F}_{1}-16-2-6-3$ & 175 & $155(88.6)$ & 384 & 2.48 & 31.3 \\
(Control) & $\mathrm{GlS}_{1} \mathrm{~F}_{1}-16-2-6-6$ & 143 & $143(100)$ & 386 & 2.70 & 32.6 \\
& $\mathrm{GlS}_{1} \mathrm{~F}_{1}-16-2-6-17$ & 170 & $157(92.4)$ & 695 & 4.43 & 35.7 \\
\hline
\end{tabular}

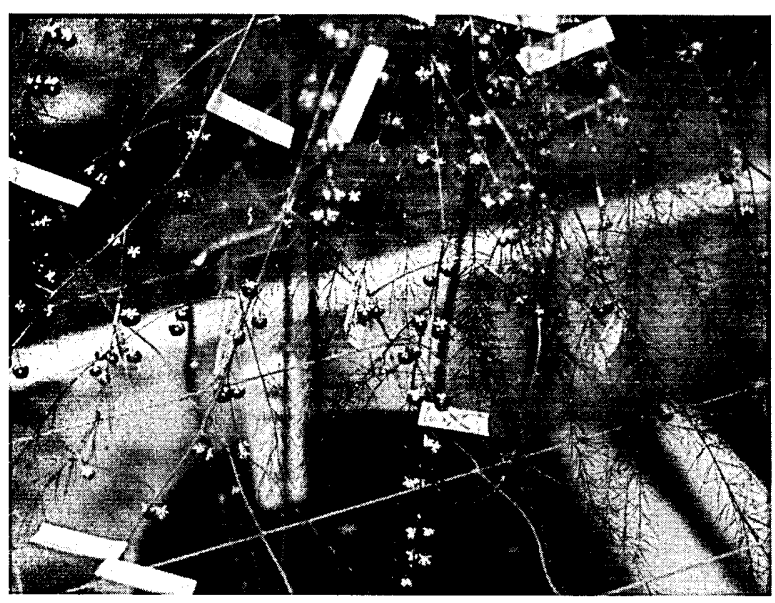

Fig. 3. Fruit set in a sex-converted (FP-1) plant. 
per fruit in the crosses except one control cross between Welcome-9201-6 and $\mathrm{GIS}_{1} \mathrm{~F}_{1}-16-2-6-17$. Average weight of a seed showed the similar values $(31.3-35.7 \mathrm{mg}$ ) in all the six crosses.

\section{DISCUSSION}

Numerous reviews have summarized the variability observed in plant regenerants from tissue cultures (Evans et al., 1984; Hammerschlag and Bauchen, 1984; Hammerschlag, 1992; Daub, 1986). Genetic stability is required for technical and commercial micropropagation system, whereas research on somaclonal variation has culminated in the release of improved cultivars of blackberry (McPheeters and Skirvin, 1989), celery (Heath-Pagliuso et al., 1989), geranium (Skirvin and Janick, 1976) and sweet potato (Moyer and Collins, 1983).

Sex-converting mutation was recognized in asparagus during somatic embryogenesis from protoplasts in the current study. Although the genotypes of sex-converted (female) plant and the control male plants were identically heterozygous in $P g m-1$ and $S k d h-1$ loci, the genotypes of sex-converted plant were homozygous in contrast to the heterozygous genotypes of control male plants in the three loci, $M d h-1, M d h-2$ and $I d h-1$. The allozyme mutation in a part of loci might have been resulted from nuclear genomic mutations, such as single nucleotide mutation, decrease of chromosome number and chromosomal rearrangements.

Single nucleotide change was reported in maize (Dennis et al., 1984). The change brings only one (or a few) modification of genes, so that this hypothesis would be neglected in the current investigation because the modification occurred in allozyme genes on three different loci and one sex determination gene.

Chromosome analysis in the somatic tissues during tissue cultures has been reported in asparagus. Kong and Chen (1988), Elmer et al. (1989) and Kunitake and Mii (1990) reported the stability of somatic chromosome number in the regenerants from protoplasts of asparagus. In contrast, Elmer et al. (1989) reported that the regenerants possessed aneuploid chromosome numbers $(2 n=22-38)$, and Kunitake et al. (1998) reported that polyploidization in embryogenic calli-derived plants increased with increasing duration of subculture, particularly when plants with low ploidy levels were used as explants. There have been, however, no reports on decrease in chromosome number during somatic embryogenesis in asparagus.

It was reported that deletion of a part of a chromosome was resulted by chromosome arm damage and often induced by radiation (Marcotrigiano and Gradziel, 1997). In case of the loss of the dominant alleles on the damaged chromosome, the hemizygous cells express the recessive traits.

Somatic crossing-over occurs when corresponding chromosome parts are exchanged between homologous chromosomes by breakage and reunion (Poethig, 1987; Suzuki et al., 1989). Somatic crossing-over was reported in soybean and tobacco (Evans and Paddock, 1976). Because of their low frequency, the likelihood of a crossing-over event occurring at the terminus of the shoot apical meristem is minimal, and most somatic crossing-over events occur somewhere else in the plant body. Visual changes of the phenotypes, such as codominant chlorophyll mutations, often provide a helpful evidence 
of somatic crossing-over since somatic crossing-over would generally go unnoticed (Evans and Paddock, 1976).

The difference of the estimated relative DNA contents between male (control) and female (sex-converted) plants was not statistically significant. Gametophytic fertility of the sex-converted plant as seed parents was also similar to that of the control female plant. If the sex-converting mutation was resulted from decrease of chromosome number or deletion of a part of a chromosome, relative DNA contents in the sex-converted and the control plants might have been different and the gametophytic fertility might have become lower in the sex-converted plant than in the control plants. Somatic crossing-over could be one of the explanations of the sex-converting mutation in this study. In this case, the sex-conversion might be the result of the change of the genotypes from "Mm" to "mm" in sex determining locus.

The three linkage pairs of Aat-1/Mdh-1, Aat-1/Idh-1 and Pgm-1/Skdh-1 were recognized previously (Ozaki et al., 2000b), and the linkage of $M d h-1$ and sex determination loci was also reported (Maestri et al., 1991). In this investigation, both of the two loci, $P g m-1$ and $S k d h-1$, were identically heterozygous in the sex-converted and control plants, whereas genotypes of the two loci, $M d h-1$ and $I d h-1$, changed to be homozygous from heterozygous in accordance with the mutation. The result of genotypic mutation in the current investigation conformed to the estimated linkage pairs of allozyme and sex determination loci.

\section{ACKNOWLEDGEMENTS}

The authors wish to express our sincere appreciation to Dr. Hiroshi Kudo, Kirin Brewery Co. Ltd., for providing plant materials and his valuable advice.

\section{REFERENCES}

Baird, W. V., A. S. Estager and J. K. Wells 1994 Estimating nuclear DNA content in peach and related diploid species using laser flow cytometry and DNA hybridization. J. Amer. Soc. Hort. Sci., 119: $1312-1316$

Daub, M. E. 1986 Tissue culture and the selection of resistance to pathogens. Ann. Rev. Phytopath., 24: $159-186$

Dennis, E. S., W. L. Gerlach, A. J. Pryor, J. L. Bennetzen, A. Inglis, D. Llewellyn, M. M. Sachs, R. J. Ferl and W. J. Peacock 1984 Molecular analysis of the alcohol dehydrogenase (Adh-1) gene of maize. Nucl. Acids Res., 12: 3983-4000

Elmer, W. H., T. Ball, M. Volokita, C. T. Stephens and K. C. Sink 1989 Plant regeneration from callus-derived protoplasts of asparagus. J. Amer. Soc. Hort. Sci., 114: 1019-1024

Evans, D. A. and E. F. Paddock 1976 Comparisons of somatic crossing over frequency in Nicotiana tabacum and three other crop species. Can. J. Genet. Cytol., 18: 57-65

Evans, D. A., W. R. Sharp and H. P. Medina-Filho 1984 Somaclonal and gametoclonal variation. Amer. J. Bot., 71: 759-774

Hammerschlag, F. A. 1992 Somaclonal variation. In "Biotechnology of Perennial Fruit Crops", ed. by F. A. Hammerschlag and R. E. Litz, CAB International, Willingford, pp. 35-55

Hammerschlag, F. A. and G. R. Bauchen 1984 Genetic stability of callus derived from peach embryos. HortScience, 19: 78 (Abstract)

Heath-Pagliuso, S., J. Pullman and L. Rappaport 1989 'UC-T3 Somaclone': Celery germplasm resistant to Fusarium oxysporum f. sp. apii., race 2. HortScience, 24: 711-712

Karp, A., R. S. Nelson, E. Thomas and S. W. J. Bright 1982 Chromosome variation in protoplast-derived 
potato plants. Theor. Appl. Genet., 63: 265-272

Kong, Y. and C. - K. Chen 1988 Culture of asparagus protoplasts on porous polypropylene membrane. Plant Cell Rep., 7: 67-69

Kunitake, H. and M. Mii 1990 Somatic embryogenesis and plant regeneration from protoplasts of asparagus (Asparagus officinalis L.). Plant Cell Rep., 8: 706-710

Kunitake, H., T. Nakashima, K. Mori and M. Tanaka 1998 Somaclonal and chromosomal effects of genotype, ploidy and culture duration in Asparagus officinalis L. Euphytica, 102: 309-316

Larkin, P. J. and W. R. Scowcroft 1981 Somaclonal variation- a novel source of variability from cell cultures for plant improvement. Theor. Appl. Genet., 60: 197-214

Löptien, H. 1979 Identification of the sex chromosome pair in asparagus (Asparagus officinalis L.). Z. Pflanzenzüch., 82: 162-173

Maestri, E., F. M. Restivo, G. P. Marziani-Longo, A. Falavigna and F. Tassi 1991 Isozyme gene markers in the dioecious species Asparagus officinalis L. Theor. Appl. Genet., 81: 613-618

Marcotrigiano, M. and T. M. Gradziel 1997 Genetic mosaics and plant improvement. Plant Breed. Rev., 15: $43-84$

Martínez, C. P., K. Arumuganathan, H. Kikuchi and E. D. Earle 1994 Nuclear DNA content of ten rice species as determined by flow cytometry. Japan. J. Genet., 69: 513-523

McCoy, T. J., R. L. Phillips and H. W. Rines 1982 Cytogenetic analysis of plants regenerated from oat (Avena sativa) tissue cultures; high frequency of partial chromosome loss. Can. J. Genet. Cytol., 24: $37-50$

McPheeters, K. and R. M. Skirvin 1989 Somaclonal variation among ex vitro 'Thornless Evergreen' trailing blackberries. Euphytica, 42: 155-162

Moyer, J. W. and W. W. Collins 1983 'Scarlet' sweet potato. HortScience, 18: 111-112

O'Brien, I. E. W., D. R. Smith, R. C. Gardner and B. G. Murray 1996 Flow cytometric determination of genome size in Pinus. Plant Sci., 115: 91-99

Ollitrault-Sammarcelli, F., J. M. Legave, N. Michaux-Ferriere and A. M. Hirsch 1994 Use of flow cytometry for rapid determination of ploidy level in the genus Actinidia. Scientia Hortic., 57: 303-313

Orton, T. J. 1983 Experimantal approaches to the study of somaclonal variation. Plant Molec. Biol. Rep., 1: 67-76

Ozaki, Y., K. Narikiyo, M. Hiramatsu, K. Ureshino and H. Okubo 1998 Application of flow cytometry for rapid determination of ploidy levels in asparagus (Asparagus officinalis L.). J. Fac. Agr., Kyushu Univ., 43: 83-88

Ozaki, Y., T. Tashiro and H. Okubo 2000a Use of allozyme variation for evaluating genetic purity in asparagus (Asparagus officinalis L.) cultivars. J. Hort. Sci. Biotech., 75: 105-110

Ozaki, Y. T. Tashiro and H. Okubo 2000b Linkage arrangement of allozyme loci in asparagus (Asparagus officinalis L.). J. Japan. Soc. Hort. Sci., 69: 440-442

Ozias-Akins, P. and R. L. Jarret 1994 Nuclear DNA content and ploidy levels in the genus Ipomoea. J. Amer. Soc. Hort. Sci., 119: 110-115

Poethig, R. S. 1987 Clonal analysis of cell lineage patterns in plant development. Amer. J. Bot., 74: 581-594

Skirvin R. M. and J. Janick 1976 Tissue culture-induced variation in scented Pelargonium spp. J. Amer. Soc. Hort. Sci., 101: 281-290

Sneep, J. 1953 The significance of andromonoecy for the breeding of Asparagus officinalis L. Euphytica, 2: 89-95

Suzuki, D. T., A. J. F. Griffiths, J. H. Miller and R. C. Lewontin 1989 An Introduction to Genetic Analysis. W. H. Freeman, New York

Wendel, J. F. and C. R. Parks 1982 Genetic control of isozyme variation in Camellia japonica L. J. Hered., 73: 197-204 